\title{
Sustainable Agricultural Groundwater Management for New Reclaimed Areas in Farafra Oasis, Western Desert of Egypt
}

\author{
Yahya Elmansy, M. S. Mohamed, Ahmed A. Hassan, A. M. El-Gindy, Peter Riad
}

\begin{abstract}
Sustainable groundwater management is an important practice of water resources engineering, especially, in case of deserts and oases where there is no source of surface water and precipitation rarely occurs. The importance increases when the only source of groundwater is a nonrenewable aquifer. This is the case of new reclaimed areas in Farafra Oasis, Western Desert of Egypt. The only source of irrigation water is groundwater extracted from the nonrenewable Nubian Sandstone Aquifer (NSA). There is a great agricultural development in Farafra Oasis as a part of the 1.5 million feddan mega project. Agricultural development, for new areas, is a must for Egypt to fulfil the increasing food demand accompanied with the increasing population growth rate. However, this development has to consider the sustainability of groundwater usage along with the social, economic, and national security aspects. Groundwater extraction rate from NSA has increased. As it is a nonrenewable aquifer, there is no groundwater recharge. Consequently, the groundwater potentiometric level (GPL) decreases with time. The traditional sustainability concept of safe yield or discharge equals recharge is not applicable on such cases. The Ministry of Water Resources and Irrigation (MWRI) of Egypt set the groundwater sustainability criteria for groundwater-dependent new reclaimed areas in Farafra Oasis, Western Desert of Egypt. Both duration and economic lifting depth, have been considered. This paper presents groundwater sustainability assessment for extraction rates, $Q_{\text {well }}=-1000,-2000,-3000,-4000$, and $-5000 \mathrm{~m}^{3} / \mathrm{d}$, to obtain the most beneficial sustainable extraction rate according to the MWRI sustainability criteria. A new groundwater-dependent reclaimed area of 10,000 feddan in Sahl Baraka, Farafra oasis, was taken as a case study area. GIS functions were used to obtain the values of unknown data and develop the initial groundwater
\end{abstract}

Revised Manuscript Received on March 17, 2020.

* Correspondence Author

Yahya Elmansy*, Irrigation and Hydraulics Department, Faculty of Engineering, Ain Shams University, Cairo, Egypt. \& Civil Engineering Department, Faculty of Engineering, The British University in Egypt. Email: yahya.elmansy@bue.edu.eg

M. S. Mohamed, Irrigation and Hydraulics Department, Faculty of Engineering, Ain Shams University, Cairo, Egypt. Email: samyfoda2@yahoo.ca

Ahmed A. Hassan, Irrigation and Hydraulics Department, Faculty of Engineering, Ain Shams University, Cairo, Egypt. Email: ahmad9657@yahoo.co.uk

M. El-Gindy, Agricultural Engineering Department, Faculty of Agriculture, Ain Shams University, Cairo, Egypt. Email elgindy47@gmail.com

Peter Riad, Irrigation and Hydraulics Department, Faculty of Engineering, Ain Shams University, Cairo, Egypt. Email: ph4318@yahoo.com

(C) The Authors. Published by Blue Eyes Intelligence Engineering and Sciences Publication (BEIESP). This is an open access article under the CC BY-NC-ND license (http://creativecommons.org/licenses/by-nc-nd/4.0/) potentiometric map. MODFLOW was used to construct a numerical model for groundwater extraction rate simulation for the case study area. This model was calibrated and used to obtain

the depression cone drawdown (DCD) associated with different extraction rates. All NSA regional drawdown rates at Farafra oasis were considered. Benefit-Deficit analysis for duration and economic lifting depth criteria are presented and show that the extraction rate of $Q_{\text {well }}=-3000 \mathrm{~m}^{3} / \mathrm{d}$ is the most beneficial sustainable extraction rate according to the MWRI adopted sustainability criteria.

Keywords: Farafra Oasis; Groundwater Sustainability; Groundwater Management; Nubian Sandstone Aquifer.

\section{INTRODUCTION}

Sustainable agricultural groundwater management is extremely important in groundwater-dependent new reclaimed areas in Farafra Oasis, Western Desert of Egypt. The only source of irrigation water for these areas is groundwater extracted from the Nubian Sandstone Aquifer (NSA). It is a nonrenewable shared aquifer between Egypt, Libya, Chad, and Sudan [1]-[9]. Groundwater in the NSA is an ancient groundwater. It was recharged to the NSA thousands of years ago during a more humid climatic period.

The traditional groundwater sustainability concept of discharge equals recharge, for NSA, is not applicable. As groundwater extraction, associated with the regional development, increases, the volume of NSA groundwater storage decreases. Consequently, the groundwater potentiometric level (GPL) decreases. Also, the GPL rate of decay is directly proportional with the annual extracted groundwater volume. So, the usage of NSA groundwater, by traditional sustainability definitions and criteria, is not sustainable. However, there is a huge volume of groundwater stored in the NSA. So, there is a very long time scale during which over exploitation and negative side effects occur. Also, there is a crucial need for regional development and its associated high economic return. Considering these factors, the concept and criteria of NSA groundwater sustainability should be differently standardized and evaluated.

Reference [10] discussed the traditional groundwater sustainability concept. It is defined as the groundwater development level which meets the requirements of the present generation without affecting the requirements of the future generations. This definition has been claimed as the evaluation of every situation should be done on case by case basis because economic problems and rights of users are differently involved in all assessments. Also,

Published By:

Blue Eyes Intelligence Engineering

\& Sciences Publication

(C) Copyright: All rights reserved.

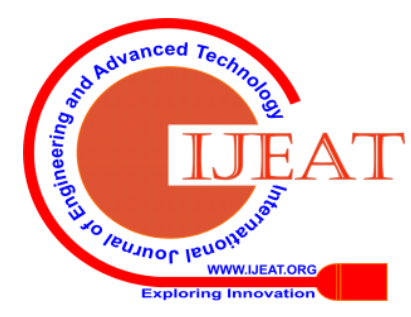


the long time scale of aquifer system response, which depends on aquifer dimensions and characteristics, has to be considered in groundwater sustainability concept. So, the sustainability criteria for groundwater management should be standardized on case by case basis [10]. The Ministry of Water Resources and Irrigation (MWRI) of Egypt, set the limits of the adopted sustainable groundwater management criteria for groundwater-dependent new reclaimed areas in Farafra Oasis [11]. These limits depend on two factors of the same weight. The first factor is the range of the economic lifting depth (ELD) (set to be $\leq 40 \mathrm{~m}$ beneath the land level (LL) at well location). The second factor is the duration during which the lifting depth (LD) becomes not economic (set to be at least 100 years). LD is the distance between the LL and the GPL at the well, including the depression cone drawdown (DCD).

A groundwater-dependent new reclaimed area of 10,000 feddan located in Sahl Baraka, Farafra oasis, Western Desert of Egypt has been considered as a case study area. It has already 40 groundwater wells with an average total depth of $750 \mathrm{~m}$. Each well serves 250 feddan. Wells data was obtained from technical reports of wells at the MWRI [12]. Fig. 1 shows a base map of Farafra Oasis including the case study area (from Google Earth). This paper presents groundwater sustainability assessment for extraction rates, $\mathrm{Q}_{\text {well }}=-1000$, $-2000,-3000,-4000$, and $-5000 \mathrm{~m}^{3} / \mathrm{d}$, to obtain the most beneficial sustainable extraction rate according to the MWRI sustainability criteria.

\section{MATERIALS AND METHODS}

The maximum value of the ELD (MAXVELD), in meters, which satisfies the ELD adopted sustainability criteria, could be represented as follows,

$$
M A X V E L D=40
$$

The minimum GPL (MINGPL) could be defined as the GPL at which the MAXVELD occurs. MINGPL, in meters, could be represented as follows,

$$
\text { MINGPL }=L L-M A X V E L D
$$

Also, the minimum duration (MINDUR), in years, which satisfies the sustainability criteria could be represented by,

$$
\text { MINDUR }=100
$$

\section{Developing the Groundwater Potentiometric Map (GPM)} for the Case Study Area

The GPL at year 2015, starting year, could be considered as the initial GPL (IGPL). The IGPL could be obtained using the no flow pressure head (NFPH), obtained from technical reports of wells, and the LL at well location as follows,

$$
I G P L=L L+N F P H
$$

Using ArcGIS interpolation methods and IGPL at locations of wells, the groundwater potentiometric map (GPM) for the case study area has been developed. The locations of wells are well distributed and covering the study area. This led to obtaining well representative GPM for the study area. This map used later for MODFLOW groundwater numerical model calibration. Fig. 2 shows the contour map for the potentiometric groundwater levels for the study area.

\section{A. Determination of NSA Regional Drawdown Rate (NSARDR) at Farafra Oasis}

Using Reference [8] NSA simulation results, three scenarios for NSA regional drawdown (NSARD) at Farafra oasis could be obtained. NSARD Scenario 1, 2, and 3 which expected to occur in case of low, moderate, and high development, in the whole aquifer area, respectively. Also, NSARD Scenario 1, 2, and 3 represents the minimum, mean, and maximum NSARD Scenario, respectively Drawdown values, obtained from [8], were plotted, correlated, and found to be increasing linearly with a NSARDR of $0.34,0.49$, and $0.74 \mathrm{~m} / \mathrm{yr}$ for NSARD Scenario 1, 2, and 3, respectively.

\section{B. MODEFLOW Numerical Groundwater Simulation Model for Case Study Area and Determination of Depression Cone Drawdown (DCD)}

As soon as groundwater issues from a well, a depression cone starts to develop. MODFLOW 2000 (version 3.1) was used to develop the groundwater flow simulation model. MODFLOW is the most commonly used numerical model for groundwater flow [13]. All wells in the wells field of the case study area were presented. The main characteristics of the groundwater flow numerical model, for the case study area;

- The water bearing formation is one confined NSA layer.

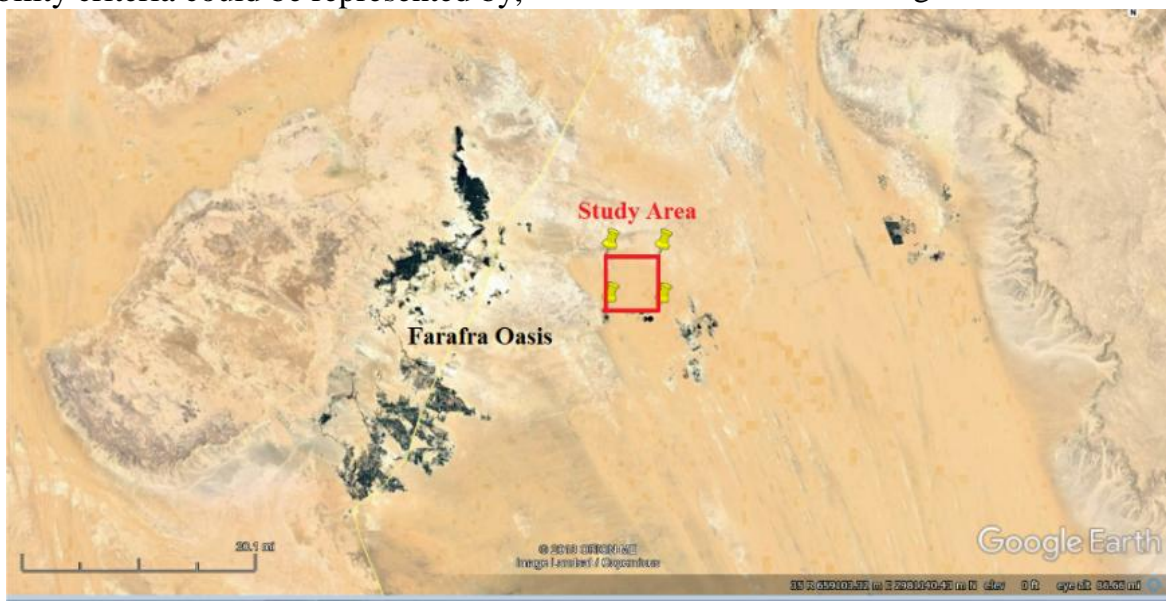

Fig. 1. Base map of Farafra Oasis including the case study area (from Google Earth)

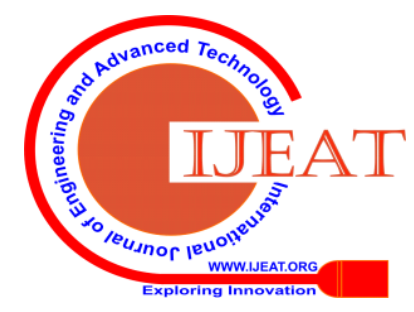




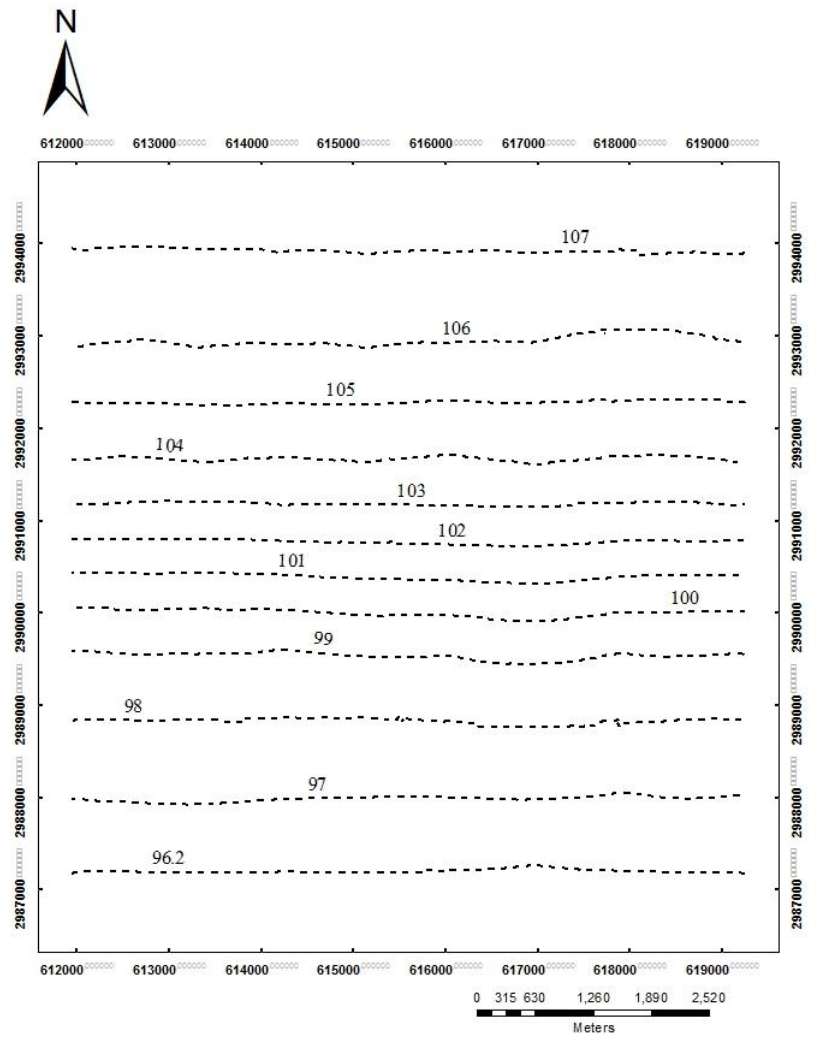

Fig. 2. Groundwater potentiometric contour map of the study area

- The groundwater flow in the confined NSA layer is governed by constant heads in North and South.

- No flow occurs in East and West directions.

- Groundwater discharge from confined NSA layer occurs through field of 40 production wells.

- Groundwater density, spatially and temporally, was assumed to be constant.

The selected solver is the Bi-Conjugate Gradient Stabilized (WHS) as it has the ability to solve simultaneous equations in both linear and non-linear systems. The advantage of the WHS solver is that it is very stable and generally converges to a solution [14].

The modeled area was $53.29 \mathrm{~km} 2 ; 7300 \mathrm{~m}$ in $\mathrm{x}$ and $\mathrm{y}$ directions. High density model grid, cell size (50m*50m), was used to obtain accurate output results. This grid consists of a finite difference mesh of 3 layers to represent the NSA aquifer, at the location of the case study area. These layers were determined from borehole soil classification of wells [12]. The average thickness of the first, second, and third layer is $134 \mathrm{~m}, 316 \mathrm{~m}$, and $279 \mathrm{~m}$, respectively. The number of rows is 146 and the number columns is 146 . Fig. 3 shows a vertical cross section passing through the case study area (column 28).

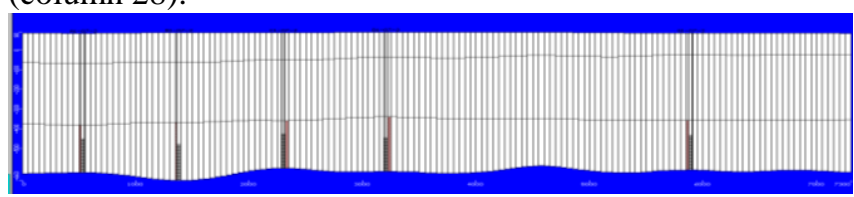

Fig. 3. Vertical cross section passing through the study area (column 28)

Boundary conditions were assigned as no-flow (Neumann conditions) in East and West directions, while Northern and Southern boundaries were assigned with constant heads of $107.0 \mathrm{~m}$ and $96.2 \mathrm{~m}$, respectively. These values were obtained from GIS extrapolation of the available data of wells.

During the calibration process, the hydraulic conductivity spatially varied until matching between observed data and model output occurred. Several runs were done to achieve this step. Also, the calibration process was done using PEST (inverse modeling) by MODFLOW. Inverse modeling adjusts the model inputs to determine the optimum set of inputs for a specific condition [15].

Table-I shows the statistical results for the steady-state calibration process which indicate the reliability of the calibrated model as the correlation coefficient is 0.999. Fig. 4 shows the model-predicted versus observed potentiometric groundwater head levels graph. It is clearly shown that the output dots are lying within the $95 \%$ confidence limits which indicate a very good calibration result. Fig. 5 shows the steady state calibrated groundwater potentiometric levels versus the observed potentiometric levels as head equipotential lines at year 2015.

After calibration process, pumping wells were added. Runs, under steady state condition, using extraction rates of $\mathrm{Q}_{\text {well }}=-1000,-2000,-3000,-4000$, and $-5000 \mathrm{~m}^{3} / \mathrm{d}$ were applied to obtain the MODFLOW groundwater potentiometric map, at year 2015, associated with every applied extraction rate. Using the MODFLOW groundwater potentiometric map, the MODFLOW GPL at every well (MFGPL), associated with every applied extraction rate, at year 2015, could be obtained.

Table- I: Summary of steady state calibration statists

\begin{tabular}{|l|l|}
\hline Time: & Steady state \\
- No. of Data Points & 40 \\
- Max. Residual & $0.405 \mathrm{~m}$ \\
- Min. Residual & $0.002 \mathrm{~m}$ \\
- Residual Mean & $0.027 \mathrm{~m}$ \\
- Absolute Residual Mean & $0.105 \mathrm{~m}$ \\
- Standard Error of the Estimate & $0.021 \mathrm{~m}$ \\
- Root Mean Squared & $0.135 \mathrm{~m}$ \\
- Normalized RMS & $1.275 \%$ \\
- Correlation Coefficient & 0.999 \\
\hline
\end{tabular}

Referring to the groundwater potentiometric contour map shown in Fig. 2 and distribution of wells in the wells field, it could be noticed that wells could be grouped into 12 groups. The locations and groups of wells are shown in Fig. 6. For every group of wells, the average of IGPL, MFGPL, LL, and MINGPL could be used as the group IGPL (GIGPL), group MFGPL (GMFGPL), group LL (GLL), and group MINGPL (GMINGPL), respectively. Fig. 7 shows the GIGPL, GLL, and GMINGPL, for all groups of wells in the case study area.

Equation (2) has been modified to calculate the GMINGPL, in meters, as follows,

$$
G M I N G P L=G L L-M A X V E L D
$$

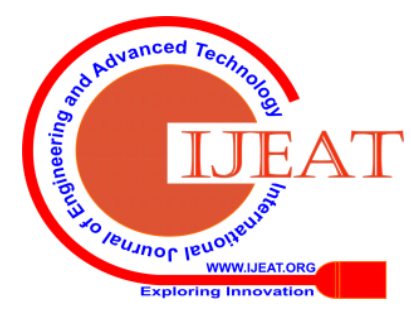




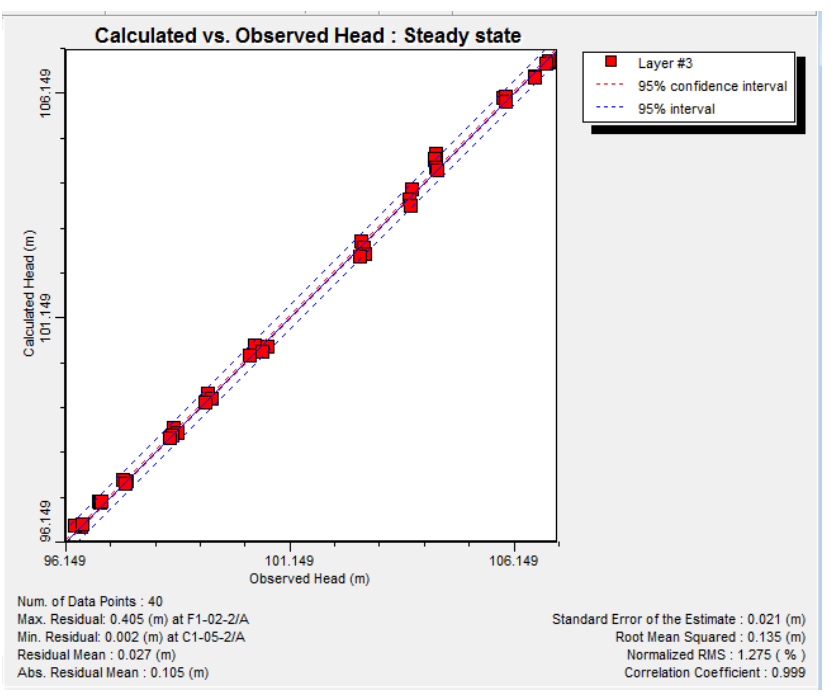

Fig. 4. Model-predicted versus observed potentiometric groundwater head levels (Steady State)

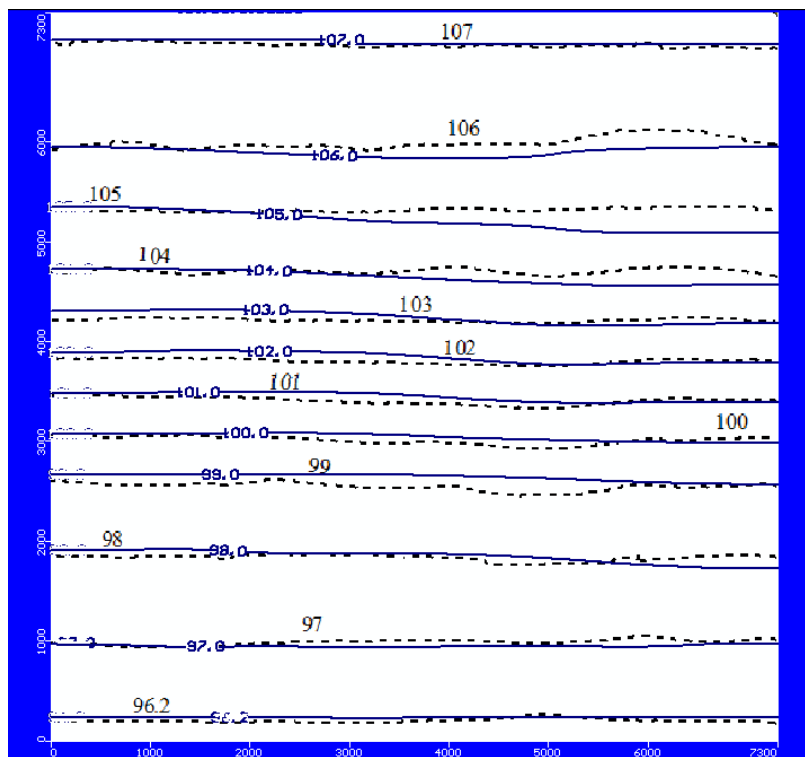

Fig. 5. Calibrated versus observed groundwater potentiometric levels at year 2015

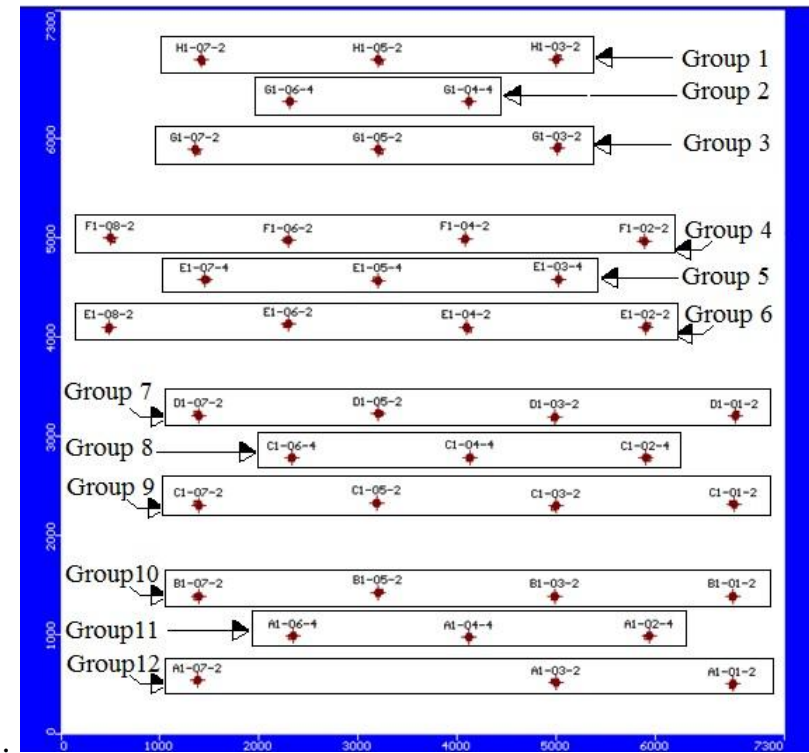

Fig. 6. Locations and groups of wells

The group DCD (GDCD), for every group of wells, could be calculated by subtracting the GMFGPL from the GIGPL, at year 2015 .

$$
G D C D=G I G P L-G M F G P L
$$

C. Determination of Group Duration (GDUR) and Group Lifting Depth after 100 years (GLD100Y)

The Group Duration (GDUR) during which the group GPL (GGPL) reaches the GMINGPL and the Group LD, after 100 years of a considered extraction rate operation (GLD100Y), at year 2115, could be calculated using (7) and (8), respectively.

$$
G D U R=\frac{G I G P L-G M I N G P L-G D C D}{N S A R D R}
$$

$$
G L D 100 Y=[G L L-G I G P L+(N S A R D R \times 100)+G D C D]
$$

\section{Benefit - Deficit Analysis}

None of the NSA drawdown scenarios can be considered as certain and/or exact scenario. All NSA drawdown scenarios can occur with the same probability and uncertainty factor. This fact must be taken into consideration in sustainability discussions.

In order to decide whether a considered extraction rate is sustainable for the case study area or not, taking into consideration all NSA drawdown scenarios, the Benefit-Deficit analysis should be used. This analysis is applicable on both duration and lifting depth sustainability criteria.

\section{- Methodology for Duration Sustainability Assessment}

For every group, if the GDUR exceeds the MINDUR, 100 years, the \%Group Duration Benefit (\%GDURB) can be obtained, for every group, considering every NSARD Scenario, as follows:

$$
\% G D U R B=\frac{G D U R-M I N D U R}{M I N D U R} \times 100
$$

Note that, the \%GDURB is a positive value. Also, if the GDUR is less than the MINDUR, 100 years, the \%Group Duration Deficit (\%GDURD) can be obtained, for every group, considering every NSARD Scenario, as follows:

$$
\% G D U R D=\frac{G D U R-M I N D U R}{M I N D U R} \times 100
$$

Note that, the \%GDURD is a negative value.

Considering all NSA drawdown scenarios, the average \%Duration Benefit (AV\%DURB), average \%Duration Deficit (AV\%DURD), and average \%Duration (B-D) (AV\%DUR(B-D)) can be calculated as follows:

$A V \% D U R B=\frac{\sum \% G D U R B}{\text { No. of Groups } \times \text { No. of NSARD Scenarios }}$

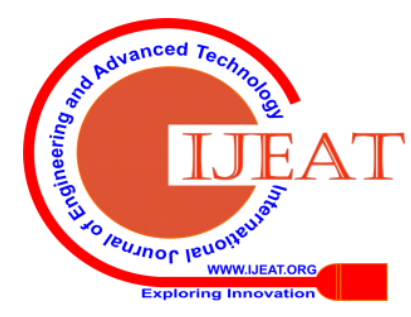




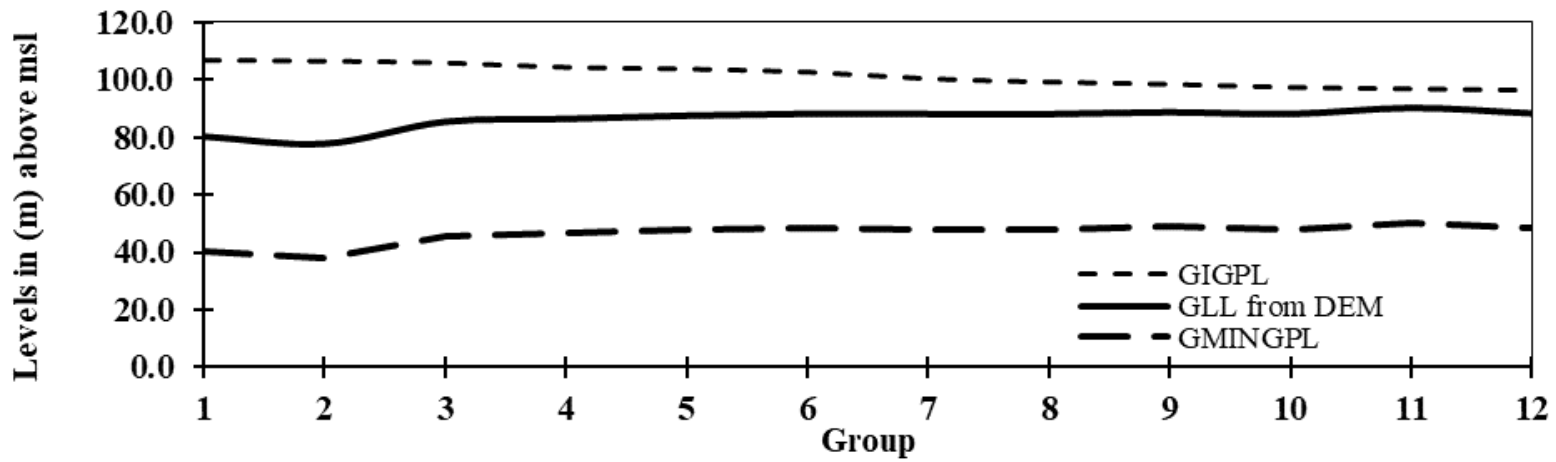

Fig. 7. GIGPL, GLL, and GMINGPL for all groups of wells

$$
A V \% D U R D=\frac{\sum \% G D U R D}{\text { No. of Groups } \times \text { No. of NSARD Scenarios }}
$$

$$
A V \% D U R(B-D)=A V \% D U R B+A V \% D U R D
$$

If the $A V \% D U R(B-D)$ is positive, this means that the probability of benefit occurrence, considering all NSA drawdown scenarios, is greater than the probability of deficit occurrence and the considered extraction rate can be considered as sustainable from the duration point of view.

\section{- Methodology for Lifting Depth Sustainability}

\section{Assessment}

For every group, If the GLD100Y is less than the MAXVELD, \%Group LD Benefit (\%GLDB) can be obtained, for every group, considering every NSARD Scenario, as follows:

$$
\% G L D B=\frac{M A X V E L D-G L D 100 Y}{M A X V E L D} \times 100
$$

Note that, the \%GLDB is a positive value.

Also, if the GLD100Y, considering a NSARD Scenario, is greater than the MAXVELD, the \%Group LD deficit (\%GLDD) can be obtained, for every group, considering every NSARD Scenario, as follows:

$$
\% G L D D=\frac{M A X V E L D-G L D 100 Y}{M A X V E L D} \times 100
$$

Note that, the \%GLDD is a negative value.

The average \%LD Benefit (AV\%LDB), average \%LD Deficit (AV\%LDD), and average \%LD (B-D) (AV\%LD(B-D)), considering all NSA drawdown scenarios, have to be determined. The AV\%LDB, AV\%LDD, and AV\%LD(B-D) can be calculated as follows:

$$
A V \% L D B=\frac{\sum \% G L D B}{\text { No. of Groups } \times \text { No. of NSARD Scenarios }}
$$

$$
A V \% L D D=\frac{\sum \% G L D D}{\text { No. of Groups } \times \text { No. of NSARD scenarios }}
$$

$$
A V \% L D(B-D)=A V \% L D B+A V \% L D D
$$

If the $A V \% L D(B-D)$ is positive, this means that the probability of benefit occurrence, considering all NSARD Scenarios, is greater than the probability of deficit occurrence and the considered extraction rate could be considered as sustainable from the LD at year 2115, after 100 years, point of view.

If both the AV\%DUR(B-D) and the AV\%LD(B-D) are positive, this means that the considered extraction rate could be considered as sustainable and could be applied to the case study area. But, if one of them is negative, the considered extraction rate could be considered as not sustainable and should not be applied to the case study area.

\section{Methodology for Determination of the Most Beneficial Sustainable Extraction Rate}

If two or more extraction rates fulfilled both sustainability criteria, duration and LD, which one would be the most beneficial sustainable extraction rate?" In other words, if extraction rate of $Q_{\text {well }}=-1000 \mathrm{~m}^{3} / \mathrm{d}$ with a positive AV\%DUR(B-D) higher than that of operation $\mathrm{Q}_{\text {well }}=-2000$ $\mathrm{m}^{3} / \mathrm{d}$, which one is better? Noting that, the higher extraction rate is the more extracted water volume and in turn is the more cultivated area and relative production yield. In order to answer this question, the extraction rate operation weight (EROW) and the Weighted AV\%DUR(B-D) for the extraction rate have to be determined. The EROW is a dimensionless parameter and can be calculated as follows,

1) Calculation of the GD40TEV for every NSARD Scenario. The GD40TEV is defined as the total extracted volume from the wells of a group until the GGPL reaches the value of GMINGPL. It can be calculated as follows, GD40TEV =

[GDUR $\times 365 \times$ Qwell $\times$ Group No.of wells ]

Where: GDUR is in years and $\mathrm{Q}_{\text {well }}$ is in $\mathrm{m}^{3} / \mathrm{d}$

2) Calculation of the Cumulative D40TEV (CUMD40TEV), for every NSARD Scenario. The CUMD40TEV is defined as the summation of the GD40TEV of all groups of wells in the study area.

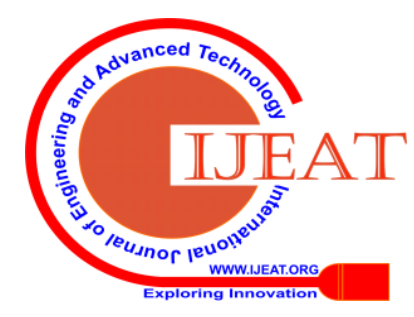


CUMD40TEV $=\sum_{1}^{\text {number of groups }}$ GD40TEV

The number of groups in the current study $=12$

3) Calculation of the Average Cumulative D40TEV (AVCUMD40TEV), considering all NSARD Scenarios, which is defined as the mean of CUMD40TEV calculated in step 2 .

$$
\text { AVCUMD40TEV }=\frac{\sum_{1}^{\text {number of scenarios }} \text { CUMD40TEV }}{\text { No. of NSARD scenarios }}
$$

The number of NSARD Scenarios $=3$

4) Calculation of the extraction rate operation weight (EROW) as follows,

$$
E R O W=\frac{A V C U M D 40 T E V}{M I N I M U M A V C U M D 40 T E V}
$$

Where: the MINIMUM AVCUMD40TEV is the AVCUMD40TEV of the minimum sustainable extraction rate.

After calculation of EROW, the Weighted AV\%DUR(B-D) for an extraction rate can be calculated as follows,

Weighted $A V \% D U R(B-D)=E R O W \times A V \% D U R(B-D)$

The extraction rate of the highest Weighted AV\%DUR(B-D) would be the most beneficial sustainable extraction rate.

\section{RESULTS AND DISCUSSIONS}

\section{A. Group Depression Cone Drawdown (GDCD) at year 2015}

The MODFLOW model was run under stresses of extraction rates $Q_{\text {well }}=-1000,-2000,-3000,-4000$, and -5000 $\mathrm{m}^{3} / \mathrm{d}$, at year 2015 (starting year). MODFLOW GPL maps were obtained, from which GMFGPL, for every group of wells, could be obtained. Then, using (6), the GDCD, for every group, could be calculated. Fig. 8 shows the resulting steady state simulation GPL map for $\mathrm{Q}_{\text {well }}=1000 \mathrm{~m}^{3} / \mathrm{d}$. Fig. 9 Shows the GDCD for all groups of wells, in the study area, at year 2015. It is noticed that the GDCD is directly proportional to the applied extraction rates.

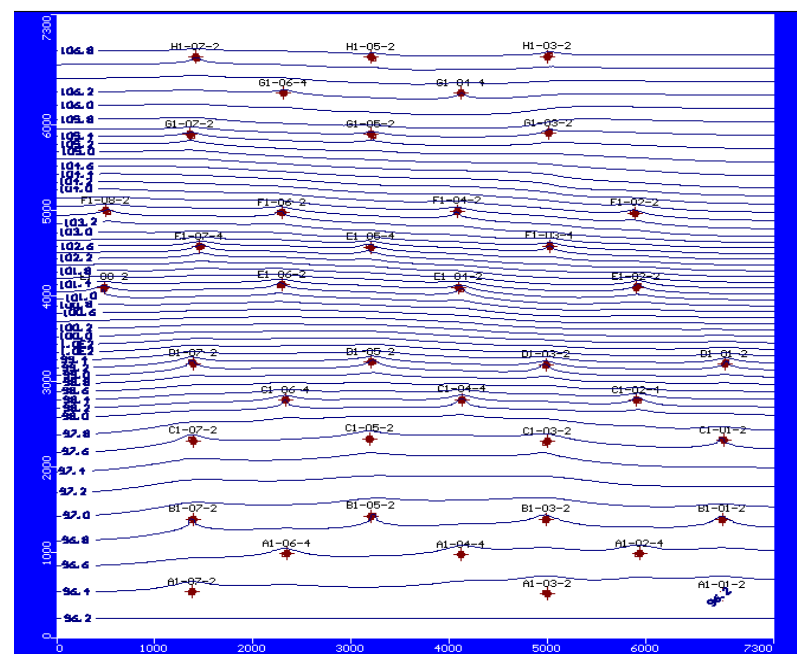

Fig. 8. GPL Map at year 2015, from MODFLOW, for Qwell = -1000 m3/d

\section{B. Sustainability Assessment for The Considered Extraction Rates}

\section{- Duration Sustainability Assessment}

Fig. 10 shows the GDUR, for every group of wells, under the stress of the minimum considered extraction rate $Q_{\text {well }}=-1000$ $\mathrm{m}^{3} / \mathrm{d}$. Considering NSARD Scenario 1 , it could be noticed that that the GDUR, for all groups, is greater than 100 years, MINDUR. However, considering NSARD Scenario 2, the GDUR, for groups 9, 10, 11, and 12, is less than 100 years, MINDUR. Also, considering NSARD Scenario 3, it could be noticed that the GDUR, for all groups, is less than MINDUR. The same behavior occurs with extraction rates of $\mathrm{Q}_{\text {well }}=$ $-2000,-3000,-4000$, and $-5000 \mathrm{~m}^{3} / \mathrm{d}$ with minor differences of number of groups at which the GDUR is less than MINDUR when NSARD Scenario 2 is considered.

Fig. 11 shows the \%GDURB \& \%GDURD for all groups, considering all NSA drawdown scenarios, under the stress of the minimum considered extraction rate $Q_{\text {well }}=-1000 \mathrm{~m}^{3} / \mathrm{d}$. Considering NSARD Scenario 1, It could be noticed that all groups are in the benefit side. Also, in case of NSARD Scenario 2, two-third of the groups are in the benefit side. However, considering NSARD Scenario 3, all groups are in the deficit side. The same situation occurs with extraction rates of $\mathrm{Q}_{\text {well }}=-2000,-3000,-4000$, and $-5000 \mathrm{~m}^{3} / \mathrm{d}$ with minor differences in the ratio of groups in the benefit side, when NSARD Scenario 2 is considered.

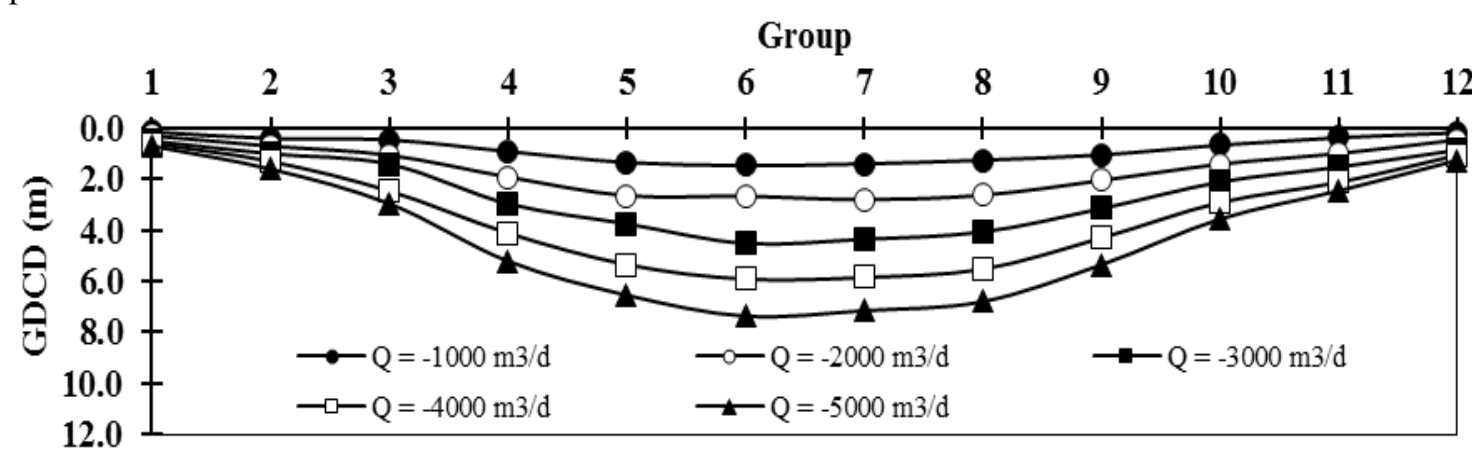

Fig. 9. Variation of GDCD with Extraction Rates (at year 2015)

Published By:

Blue Eyes Intelligence Engineering \& Sciences Publication

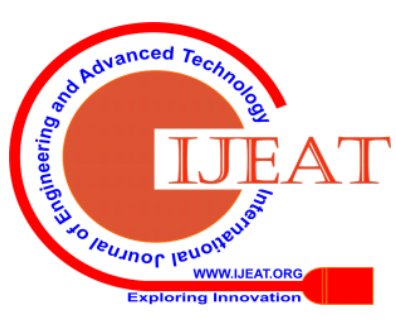




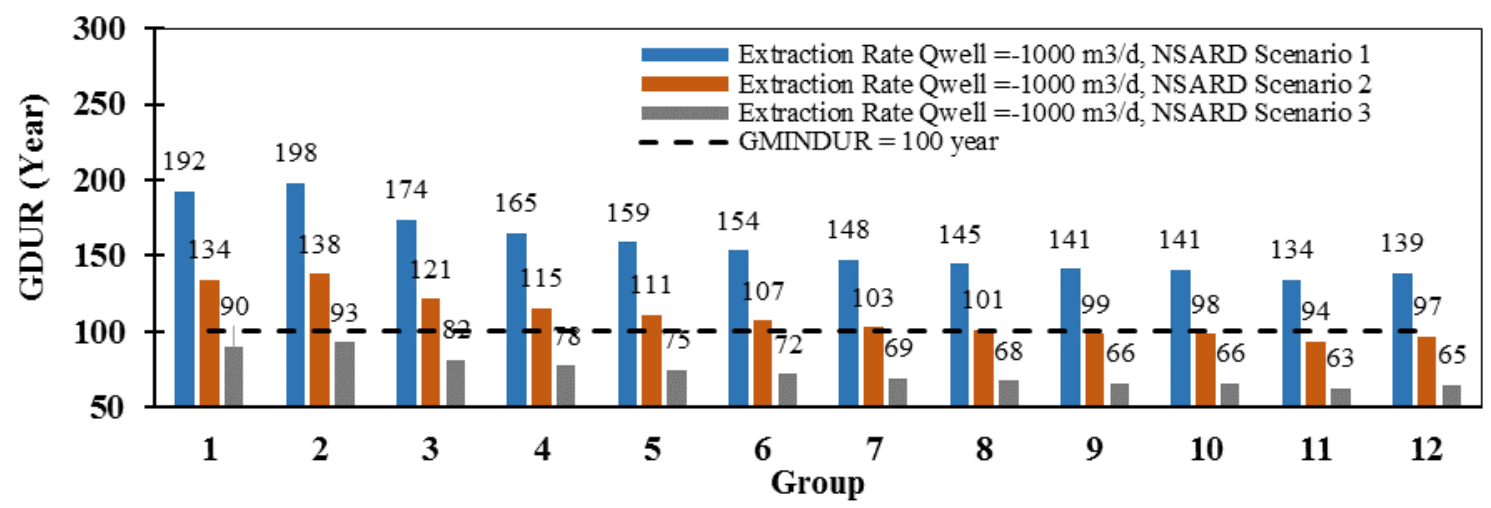

Fig. 10. GDUR under the stress of the minimum considered extraction rate Qwell $=-1000 \mathrm{~m} 3 / \mathrm{d}$

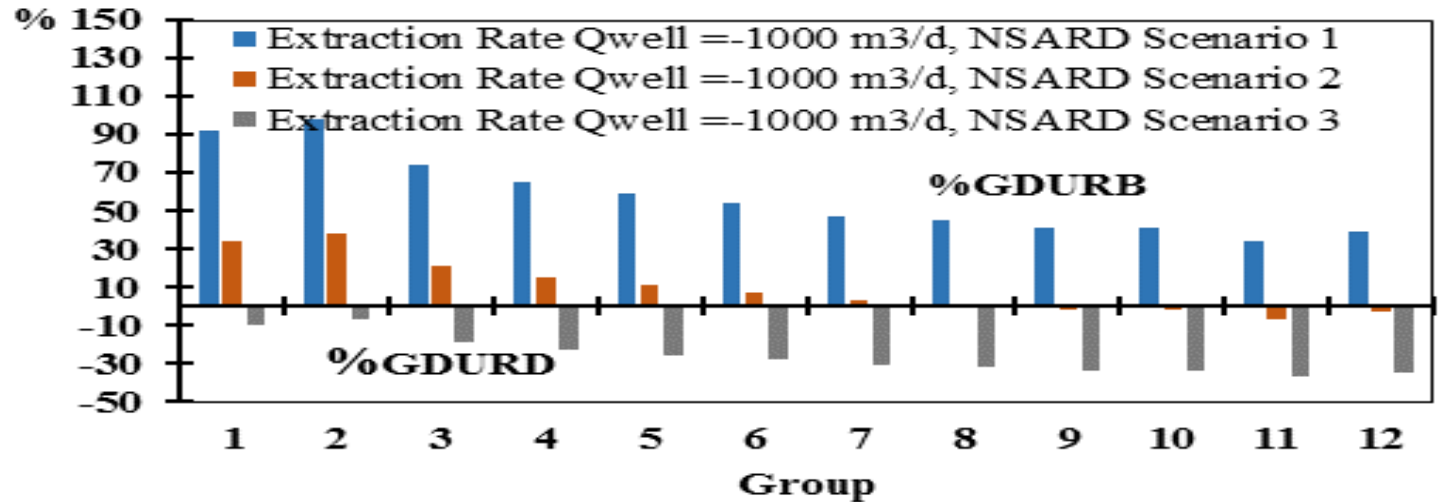

Fig. 11. \%GDURB and \%GDURD for Qwell = -1000 m3/d

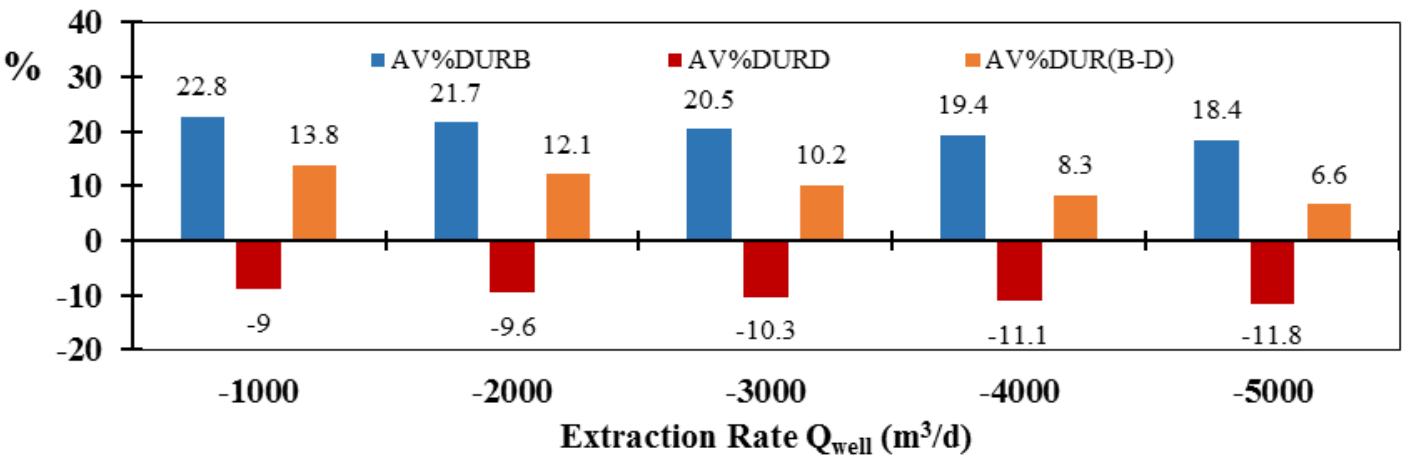

Fig. 12. AV\%DURB, AV\%DURD, and AV\%DUR(B-D) for all considered extraction rates

Using (11), (12), and (13), the AV\%DURB, AV\%DURD, and AV\%DUR(B-D), for all considered extraction rates, was calculated. Fig. 12 shows the calculated AV\%DURB, AV\%DURD, and AV\%DUR(B-D), for all considered extraction rates. it could be noticed that the AV\%DUR(B-D) decreases as the extraction rate increases with maximum value of $13.8 \%$ and minimum value of $6.6 \%$ for extraction rate $Q_{\text {well }}=-1000$ and $-5000 \mathrm{~m}^{3} / \mathrm{d}$, respectively. All values of AV\%DUR(B-D), for all considered extraction rates, are positive. So, all considered extraction rates can be considered as sustainable from the duration point of view. However, the sustainability of LD, after extraction rate operation of 100 years, for every considered extraction rate, has to be assessed.

\section{- Lifting Depth Sustainability Assessment}

Fig. 13 shows the GLD100Y, for every group of wells, under the stress of the minimum considered extraction rate, $\mathrm{Q}_{\text {well }}=-1000 \mathrm{~m}^{3} / \mathrm{d}$, for NSARD Scenarios 1, 2, and 3 . Considering NSARD Scenario 1, it could be noticed that that the GLD100Y, for all groups, is less than $40 \mathrm{~m}$, MAXVELD. However, considering NSARD Scenario 2, the GLD100Y for groups $9,10,11$, and 12 is greater than $40 \mathrm{~m}$, MAXVELD. Especially, group 11 because it has the maximum GLL and relatively low GIGPL, refer to Fig. 7. Also, considering NSARD Scenario 3, it could be noticed that the GLD100Y, for all groups, is greater than MAXVELD.

Also, the GLD100Y was calculated, for every group of wells, under the stress of extraction rates of Qwell $=-2000$, $-3000,-4000$, and $-5000 \mathrm{~m} 3 / \mathrm{d}$. The same behavior occurs as that of the minimum considered extraction rate, Qwell = $-1000 \mathrm{~m} 3 / \mathrm{d}$ with minor differences in the number of groups at which the GLD100Y exceeds the MAXVELD when NSARD Scenario 2 is considered.

Published By:

Blue Eyes Intelligence Engineering \& Sciences Publication (C) Copyright: All rights reserved.

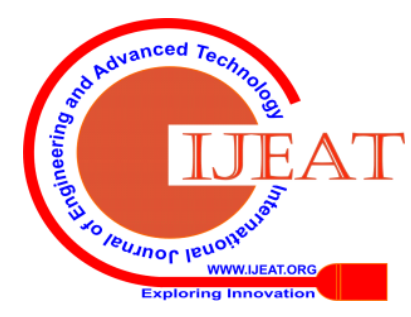




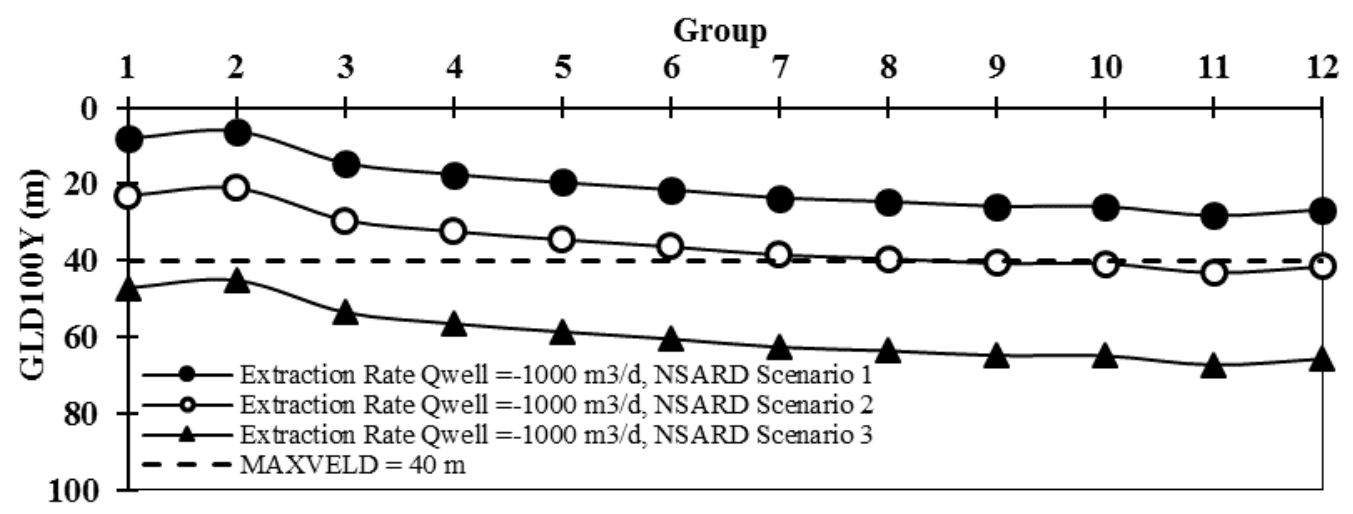

Fig. 13. GLD100Y under the stress of the minimum considered extraction rate Qwell $=-1000 \mathrm{~m} 3 / \mathrm{d}$

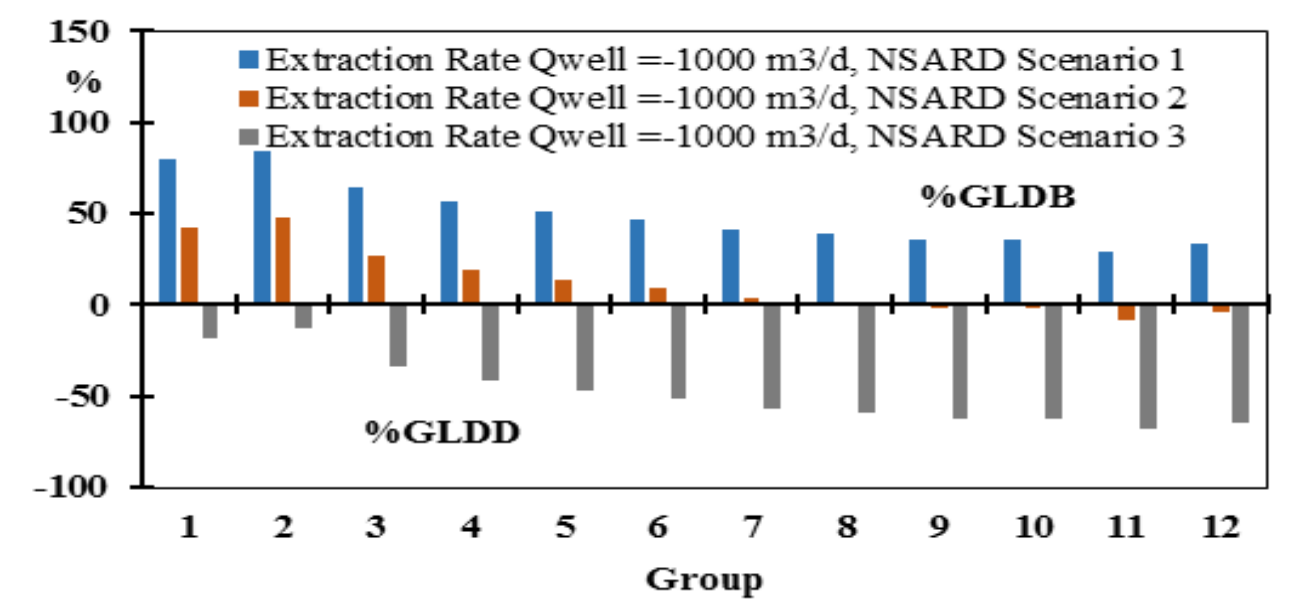

Fig. 14. \% Group LD Benefit and \% Group LD Deficit

Fig. 14 shows the \%GLDB \& \%GLDD, for all groups, for all NSARD Scenarios under the stress of the minimum considered extraction rate, $\mathrm{Q}_{\text {well }}=-1000 \mathrm{~m}^{3} / \mathrm{d}$. Considering NSARD Scenario 1, It could be noticed that GLD, for all groups, is in the benefit side. Also, in case of NSARD Scenario 2, the GLD of two-third of the groups are in the benefit side. However, considering NSARD Scenario 3, the GLD, for all groups, is in the deficit side. The same situation occurs with extraction rates of $Q_{\text {well }}=-2000,-3000,-4000$, and $-5000 \mathrm{~m}^{3} / \mathrm{d}$ with minor differences in the ratio of groups in the benefit side, when NSARD Scenario 2 is considered.

Using (16), (17), and (18), the AV\%LDB, AV\%LDD, and AV\%LD(B-D), for all considered extraction rates, could be calculated. Fig. 15 shows the calculated AV\%LDB, AV\%LDD, and AV\%LD(B-D), for all considered extraction rates. It is noticed that the $A V \% \operatorname{LD}(B-D)$ decreases as the extraction rate increases with maximum value of $5.5 \%$ and minimum value of $-3.9 \%$ for extraction rate $Q_{\text {well }}=-1000$ and $-5000 \mathrm{~m}^{3} / \mathrm{d}$, respectively. The values of $\mathrm{AV} \% \mathrm{LD}(\mathrm{B}-\mathrm{D})$, for extraction rates $Q_{\text {well }}=-1000,-2000$, and $-3000 \mathrm{~m}^{3} / \mathrm{d}$, are positive. This means that the probability of the benefit occurrence, considering all NSARD Scenarios, is greater than the probability of deficit occurrence. So, extraction rates $\mathrm{Q}_{\text {well }}$ $=-1000,-2000$, and $-3000 \mathrm{~m}^{3} / \mathrm{d}$ can be considered as sustainable, from the LD point of view. However, the values of AV\%LD(B-D), for extraction rates $Q_{\text {well }}=-4000$ and -5000 $\mathrm{m}^{3} / \mathrm{d}$ are negative. So, extraction rates $Q_{\text {well }}=-4000$ and -5000 $\mathrm{m}^{3} / \mathrm{d}$ can be considered as not sustainable and should be avoided and excluded from the applicable extraction rates.

\section{Determination of the Most Beneficial Sustainable Extraction Rate}

Having discussed the sustainability assessment for the considered extraction rates. The extraction rates $\mathrm{Q}_{\text {well }}=$ $-1000,-2000$, and $-3000 \mathrm{~m}^{3} / \mathrm{d}$ can be considered as sustainable, from both duration and economic lifting depth point of views. In order to determine the most beneficial sustainable extraction rate, the EROW and Weighted AV\%DUR(B-D), for every sustainable extraction rate, have to be determined.

Using (22), the EROW for the sustainable extraction rates $\mathrm{Q}_{\text {well }}=-1000,-2000$, and $-3000 \mathrm{~m}^{3} / \mathrm{d}$, was calculated and found to be $1,1.97$, and 2.90, respectively. The Weighted AV\%DUR(B-D), using (23), was calculated for the sustainable extraction rates $\mathrm{Q}_{\text {well }}=-1000,-2000$, and -3000 $\mathrm{m}^{3} / \mathrm{d}$ and found to be $13.8 \%, 23.8 \%$, and $29.6 \%$, respectively. So, the most beneficial sustainable extraction rate for the study area, according to the adopted sustainability criteria, is $\mathrm{Q}_{\text {well }}=-3000 \mathrm{~m}^{3} / \mathrm{d}$. Fig. 16 shows the AV\%DUR(B-D) and Weighted AV\%DUR(B-D) for the sustainable extraction rates. 


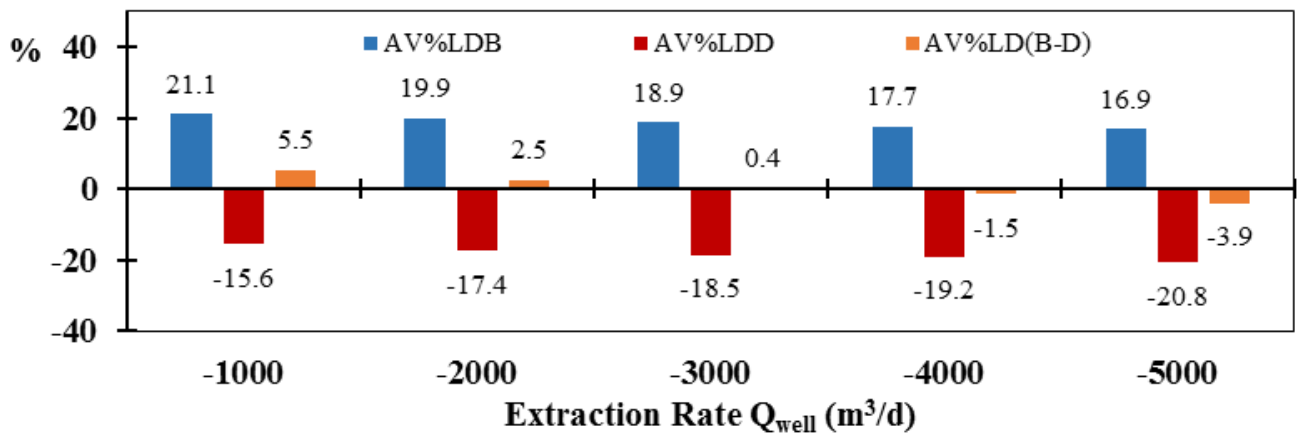

Fig. 15. AV\%LDB, AV\%LDD, and AV\%LD(B-D) for all considered extraction rates

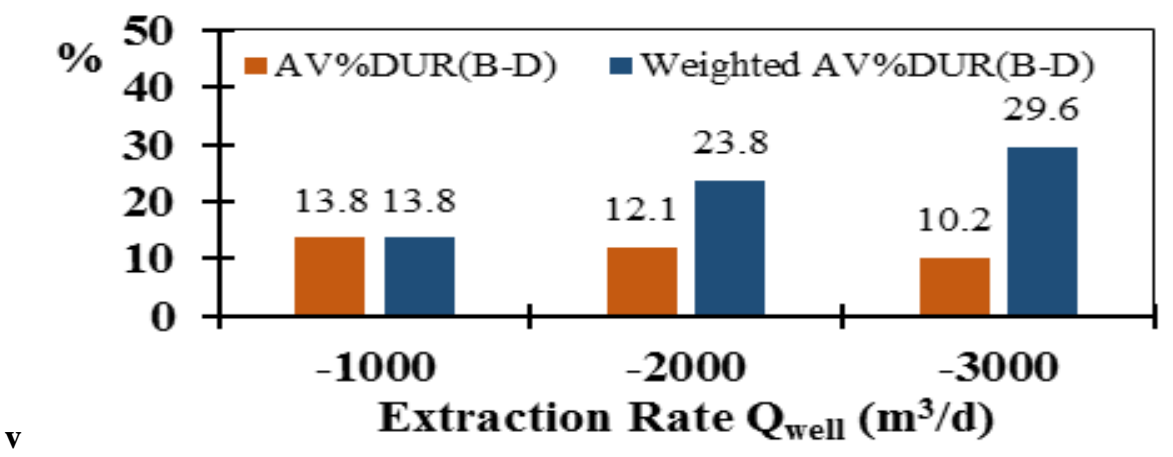

Fig. 16. AV\%DUR(B-D) and Weighted AV\%DUR(B-D) for the sustainable extraction rates

\section{CONCLUSION}

Sustainable agricultural groundwater management is extremely important for groundwater-dependent new reclaimed areas in Farafra Oasis, Western Desert of Egypt. The nonrenewable Nubian Sandstone Aquifer (NSA) is the only source of groundwater for these areas. The Ministry of Water Resources and Irrigation (MWRI) of Egypt set the groundwater sustainability criteria for these areas. Both duration and economic lifting depth, have been considered. Groundwater sustainability for extraction rates $Q_{\text {well }}=-1000$, $-2000,-3000,-4000$, and $-5000 \mathrm{~m}^{3} / \mathrm{d}$ have been assessed, according to the MWRI adopted sustainability criteria. A new groundwater-dependent reclaimed area of 10,000 feddan in Sahl Baraka, Farafra oasis, was taken as a case study area. GIS functions were used to develop the initial groundwater potentiometric map. MODFLOW model, for the study area, was constructed, calibrated, and run to obtain the depression cone drawdown (DCD) associated with different extraction rates. All NSA regional drawdown rates at Farafra oasis were considered.

Methodologies for duration and lifting depth sustainability assessment, using Benefit-Deficit analysis, have been developed and applied. Also, methodology for determination of the most beneficial sustainable extraction rate has been developed and applied. All considered extraction rates can be considered as sustainable from the duration point of view. However, extraction rates $Q_{\text {well }}=-4000$ and $-5000 \mathrm{~m}^{3} / \mathrm{d}$ are considered as not sustainable, from the economic lifting depth after 100 years point of view, and should be avoided and excluded from the applicable extraction rates.

The Weighted AV\%DUR(B-D) was calculated for the sustainable extraction rates $\mathrm{Q}_{\text {well }}=-1000,-2000$, and -3000 $\mathrm{m}^{3} / \mathrm{d}$ and found to be $13.8 \%, 23.8 \%$, and $29.6 \%$, respectively. So, the most beneficial sustainable extraction rate for the study area, according to the adopted sustainability criteria, is $\mathrm{Q}_{\text {well }}=-3000 \mathrm{~m}^{3} / \mathrm{d}$.

\section{REFERENCES}

1. A. M. Ebraheem, S. Riad, P. Wycisk, and A. M. Seif El-Nasr, "Simulation of impact of present and future groundwater extraction from the non-replenished Nubian Sandstone Aquifer in southwest Egypt," Environ. Geol., vol. 43, no. 1-2, pp. 188-196, 2002, doi: 10.1007/s00254-002-0643-7.

2. A. M. Ebraheem, S. Riad, P. Wycisk, and A. M. Sefelnasr, "A local-scale groundwater flow model for groundwater resources management in Dakhla Oasis, SW Egypt,” Hydrogeol. J., vol. 12, no. 6, pp. 714-722, 2004, doi: 10.1007/s10040-004-0359-8.

3. A. M. Ebraheem, H. K. Garamoon, S. Riad, P. Wycisk, and A. M. Seif El Nasr, "Numerical modeling of groundwater resource management options in the East Oweinat area, SW Egypt," Environ. Geol., vol. 44, no. 4, pp. 433-447, 2003, doi: 10.1007/s00254-003-0778-1.

4. E. Ghoneim and F. El-Baz, "The application of radar topographic data to mapping of a mega-paleodrainage in the Eastern Sahara," J. Arid Environ., vol. 69, no. 4, pp. 658-675, 2007, doi: 10.1016/j.jaridenv.2006.11.018.

5. W. Gossel, A. M. Ebraheem, and P. Wycisk, "A very large scale GIS-based groundwater flow model for the Nubian sandstone aquifer in Eastern Sahara (Egypt, northern Sudan and eastern Libya)," Hydrogeol. J., vol. 12, no. 6, pp. 698-713, 2004, doi: 10.1007/s10040-004-0379-4.

6. W. Gossel, A. M. Sefelnasr, P. Wycisk, and A. M. Ebraheem, “A gis-based flow model for groundwater resources management in the development areas in the eastern sahara, Africa," Appl. Groundw. Stud. Africa, pp. 43-64, 2008, doi: 10.1201/9780203889497.ch4.

7. A. Sefelnasr, W. Gossel, and P. Wycisk, "Three-dimensional groundwater flow modeling approach for the groundwater management options for the Dakhla oasis, Western Desert, Egypt," Environ. Earth Sci., vol. 72, no. 4, pp. 1227-1241, 2014, doi: 10.1007/s12665-013-3041-4.

8. A. Sefelnasr, W. Gossel, and P. Wycisk, "Groundwater management options in an arid environment: The Nubian Sandstone Aquifer System, Eastern Sahara,” J. Arid Environ., vol. 122, pp. 46-58, 2015, doi: 10.1016/j.jaridenv.2015.06.009.

9. C. I. Voss and S. M. Soliman, "The transboundary non-renewable Nubian Aquifer System of Chad, Egypt, Libya and Sudan: classical groundwater questions and parsimonious hydrogeologic analysis and modeling," Hydrogeol. J., vol. 22, no. 2, pp. 441-468, 2014, doi: 10.1007/s10040-013-1039-3.

Published By:

Blue Eyes Intelligence Engineering \& Sciences Publication

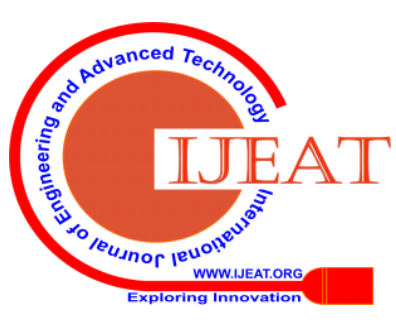


10. P. J. C. Morris, B L, Lawrence, A R L, Chilton and B. A. Adams, B, Calow R C and Klinck, "Groundwater and its Susceptibility to Degradation: A Global Assessment of the Problem and Options for Management. Early Warning and Assessment Report Series," 2003.

11. YouTube, "The Minister of Water Resources and Irrigation speech in the opening ceremony of 1.5 million feddan mega project (2015). YouTube video added by Akhbar El yom TV [online]. Available at: https://youtu.be/P9cc12At0N0," Egypt, 2015.

12. MWRI, "Technical reports of groundwater wells for reclamation of 10000 feddan, Sahl Baraka, Farafra Oasis." 2014.

13. W. Y. Abu-El-Sha'r and R. I. Hatamleh, "Using modflow and MT3D groundwater flow and transport models as a management tool for the Azraq groundwater system," Jordan J. Civ. Eng., vol. 1, no. 2, pp. 153-172, 2007.

14. Waterloo Hydrogeologic Inc., "Visual MODFLOW v.4.2 User's Manual, (2006), Professional Applications in Three-Dimensional Groundwater Flow and Contaminant Transport Modeling."

15. J. Doherty, "Ground water model calibration using pilot points and regularization," Ground Water, vol. 41, no. 2, pp. 170-177, 2003, doi: 10.1111/j.1745-6584.2003.tb02580.x

\section{AUTHORS PROFILE}

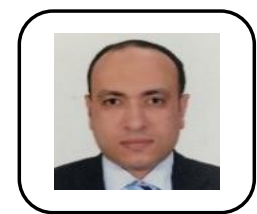

Eng. Yahya Elmansy, Assistant Lecturer, Civil Engineering Department, Faculty of Engineering, The British University in Egypt. M.Sc. in Civil Engineering, Irrigation and Hydraulics Department, Faculty of Engineering, Ain Shams University, Cairo, Egypt. Currently, he is a Ph.D. student in Irrigation and Hydraulics Department, Faculty of Engineering, Ain Shams University, Cairo, Egypt.

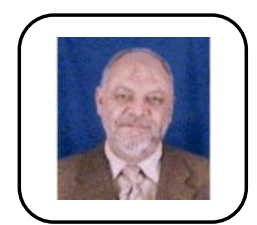

Dr. Mahmoud Samy Abd-Elsalam Mohamed Fouda, Professor of Hydraulics, Irrigation and Hydraulics Department, Faculty of Engineering, Ain Shams University, Cairo, Egypt. B.Sc. and M.Sc. in Civil Engineering, Ain Shams University, Cairo, Egypt. Ph.D. in Civil Engineering, Windsor University, Windsor, Ontario., Canada, May 1990. He has 38 years teaching experience: 6 years in Canada -2 years Visiting Professor in Arab Countries - Teaching several courses in the BUE. Also, he has been working for 22 years as an international and national consultant in water recourses and coastal engineering fields. He has practical experience in design and consultation of land reclamation projects, hydrological studies, shore protection, environmental studies, and water distribution system for Fish Farms. He has many publications in the field of Hydraulics and water resources engineering.

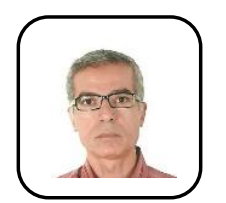

Dr. Ahmed A. Hassan, Professor of Environmental Hydrology, Irrigation and Hydraulics Department, Faculty of Engineering, Ain Shams University, Cairo, Egypt. He studied Civil Engineering at Ain Shams University from 1975 to 1980 . He was awarded his Master of Science in Ain Shams University and conducted his Ph.D. research work in Technical University of Braunschweig in Germany from 1986 to 1988. His promotion was in Ain Shams University in 1989 and the topic of his Ph.D. was "Groundwater Quantity and Quality Modeling with Applications in Arid Regions". He developed a 2-D finite element model for simulating groundwater flow and contaminant transport in porous media. Hassan worked as a Demonstrator from 1980 to 1984, Assistant lecturer from 1984 to 1988, Lecturer from 1989 to 1995 and Assistant Professor from 1995 to 2001 in the Irrigation and Hydraulics Department of the Faculty of Engineering, Ain Shams University. He has been working as Professor of Environmental Hydrology in Ain Shams University since 2001. His published research articles are more than 60 in the fields of Irrigation, Hydraulics and Hydrology and he supervised many of the M.Sc. and Ph.D. candidates in all Egyptian Universities. Prof. Hassan is a member of the Egyptian Syndicate of Engineers as well as the Egyptian Society of Civil Engineers. He works also as a consultant in the fields of Water Engineering and Hydrology and he designed and supervised many important projects in Egypt as well as some of the Arab countries.

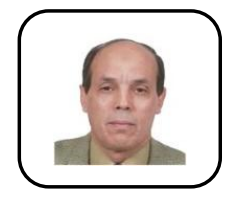

Dr. Abdel-Ghany M. El-Gindy, Professor of Agricultural Engineering \&Former Dean-Faculty of Agriculture, Ain Shams University, Egypt. B. SC in Agricultural Engineering- Alexandria University 1967. M.Sc. in Agricultural Engineering (On- farm Irrigation Engineering \& Management)Ain Shams University
1972. and Ph. D. in Agricultural Engineering (On- farm Irrigation Engineering \& Management) -Irrigation Research Institute, Sarvas, Hungary, 1977. He obtained First Class Medal of Science and Arts- 2014 and State Award in the Advanced Technological Agricultural Sciences, 2012. He has many publications in Agricultural Engineering( On-Farm Irrigation Engineering \&Management .He is International Expert of On-Farm Irrigation Engineering \&Management.

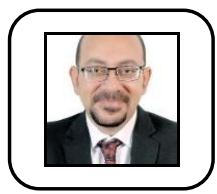

Dr. Peter Riad is graduated from Irrigation and Hydraulics Department, Faculty of Engineering-Ain Shams University in Cairo-Egypt. He got his MSc. from IHE-Delft in 2008 and finished his $\mathrm{PhD}$ at University of Hannover, Germany in 2012. He has many publications in water structures, groundwater hydrology, water management using GIS and Remote Sensing. He is a member in German-Egyptian Water Cluster and many other water organizations.

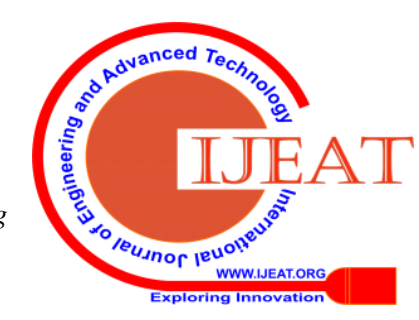

